\title{
Effects of early life stage exposure of largemouth bass to atrazine or a model estrogen ( $17 \alpha$-ethinylestradiol)
} \author{
Nicks ${ }^{1}$, James L Zajicek ${ }^{1}$, Vicki S Blazer ${ }^{4}$, Donald E Tillitt ${ }^{1}$ \\ ${ }^{1}$ Columbia Environmental Research Center, United States Geological Survey, Columbia, Missouri, United States \\ 2 Fort Collins Science Center, United States Geological Survey, Fort Collins, Colorado, United States \\ 3 Department of Biology, University of North Carolina at Greensboro, Greensboro, NC, United States \\ 4 Leetown Science Center, United States Geological Survey, Kearneysville, WV, United States \\ Corresponding Author: Jessica K Leet \\ Email address: jleet@usgs.gov
}

Jessica K Leet ${ }^{\text {Corresp., } 1}{ }^{\text {, Catherine A Richter }}{ }^{1}$, Robert S Cornman ${ }^{2}$, Jason P Berninger ${ }^{1}$, Ramji K Bhandari ${ }^{3}$, Diane K

Endocrine disrupting contaminants are of continuing concern for potentially contributing to reproductive dysfunction in largemouth and smallmouth bass in the Chesapeake Bay watershed (CBW) and elsewhere. Exposures to atrazine (ATR) have been hypothesized to have estrogenic effects on vertebrate endocrine systems. The incidence of intersex in male smallmouth bass from some regions of CBW has been correlated with ATR concentrations in water. Fish early life stages may be particularly vulnerable to ATR exposure in agricultural areas, as a spring influx of pesticides coincides with spawning and early development. Our objectives were to investigate the effects of early life stage exposure to ATR or the model estrogen $17 \alpha$-ethinylestradiol (EE2) on sexual differentiation and gene expression in gonad tissue. We exposed newly hatched largemouth bass (LMB, Micropterus salmoides) from 7 to 80 days post-spawn to nominal concentrations of 1,10 , or $100 \mu \mathrm{g} \mathrm{ATR/L} \mathrm{or} 1$ or $10 \mathrm{ng}$ EE2/L and monitored histological development and transcriptomic changes in gonad tissue. We observed a nearly $100 \%$ female sex ratio in LMB exposed to EE2 at $10 \mathrm{ng} / \mathrm{L}$, presumably due to sex reversal of males. Many gonad genes were differentially expressed between sexes. Multidimensional scaling revealed clustering by gene expression of the $1 \mathrm{ng} \mathrm{EE} 2 / \mathrm{L}$ and $100 \mu \mathrm{g}$ ATR/L-treated male fish. Some pathways responsive to EE2 exposure were not sex-specific. We observed differential expression in male gonad in LMB exposed to EE2 at $1 \mathrm{ng} / \mathrm{L}$ of several genes involved in reproductive development and function, including star, cyp1la2, ddx4 (previously vasa), wnt5b, cypla, and samhd1. Expression of star, cyp11a2, and cypla in males were also responsive to ATR exposure. Overall, our results confirm that early development is a sensitive window for estrogenic endocrine disruption in LMB and are consistent with the hypothesis that ATR exposure induces some estrogenic responses in the developing gonad. However, ATR-specific and EE2-specific responses were also observed. 


\section{Effects of early life stage exposure of largemouth bass to}

\section{2 atrazine or a model estrogen (17 $\alpha$-ethinylestradiol)}

3

4 Jessica K. Leet ${ }^{1 *}$, Catherine A. Richter ${ }^{1}$, Robert S. Cornman ${ }^{2}$, Jason P. Berninger ${ }^{1}$, Ramji K.

5 Bhandari $^{3}$, Diane K. Nicks ${ }^{1 \dagger}$, James L. Zajicek ${ }^{1}$, Vicki S. Blazer ${ }^{4}$, and Donald E. Tillitt ${ }^{1}$

6

$7{ }^{1}$ Columbia Environmental Research Center, United States Geological Survey, Columbia,

8 Missouri, United States of America

${ }^{2}$ Fort Collins Science Center, United States Geological Survey, Fort Collins, Colorado, United States of America

${ }^{3}$ Department of Biology, University of North Carolina at Greensboro, Greensboro, North Carolina, United States of America

${ }^{4}$ Leetown Science Center, United States Geological Survey, Kearneysville, West Virginia, United States of America

* Corresponding author:

21 Jessica K. Leet

22 Columbia Environmental Research Center, United States Geological Survey, Columbia,

23 Missouri, United States of America

24 E-mail: jleet@usgs.gov

$27 \dagger$ Deceased 


\section{Abstract}

29 Endocrine disrupting contaminants are of continuing concern for potentially contributing to 30 reproductive dysfunction in largemouth and smallmouth bass in the Chesapeake Bay watershed

31 (CBW) and elsewhere. Exposures to atrazine (ATR) have been hypothesized to have estrogenic 32 effects on vertebrate endocrine systems. The incidence of intersex in male smallmouth bass from some regions of CBW has been correlated with ATR concentrations in water. Fish early life stages may be particularly vulnerable to ATR exposure in agricultural areas, as a spring influx of pesticides coincides with spawning and early development. Our objectives were to investigate the effects of early life stage exposure to ATR or the model estrogen $17 \alpha$-ethinylestradiol (EE2) on sexual differentiation and gene expression in gonad tissue. We exposed newly hatched largemouth bass (LMB, Micropterus salmoides) from 7 to 80 days post-spawn to nominal concentrations of 1,10 , or $100 \mu \mathrm{g}$ ATR/L or 1 or $10 \mathrm{ng}$ EE2/L and monitored histological development and transcriptomic changes in gonad tissue. We observed a nearly $100 \%$ female sex ratio in LMB exposed to EE2 at $10 \mathrm{ng} / \mathrm{L}$, presumably due to sex reversal of males. Many gonad genes were differentially expressed between sexes. Multidimensional scaling revealed clustering by gene expression of the $1 \mathrm{ng}$ EE2/L and $100 \mu \mathrm{g}$ ATR/L-treated male fish. Some pathways responsive to EE2 exposure were not sex-specific. We observed differential expression in male gonad in LMB exposed to EE2 at $1 \mathrm{ng} / \mathrm{L}$ of several genes involved in reproductive development and function, including star, cypl 1a2, $d d x 4$ (previously vasa), wnt5b, cypla, and samhd1.

47 Expression of star, cypl 1a2, and cypla in males were also responsive to ATR exposure. Overall, 48 our results confirm that early development is a sensitive window for estrogenic endocrine 49 disruption in LMB and are consistent with the hypothesis that ATR exposure induces some 
50 estrogenic responses in the developing gonad. However, ATR-specific and EE2-specific

51 responses were also observed.

52

\section{Introduction}

Early life stages in fish and other vertebrates tend to be sensitive to effects of endocrine disrupting chemicals (EDCs) (van Aerle et al. 2002), and EDCs are considered a global concern. Effects during gonad development are likely to be permanent, organizational events with potential for complete sex reversal, in contrast to the generally reversible, activational effects that occur during adulthood. Fish early life stages are of particular concern in agricultural areas, as a spring influx of pesticides coincides with spawning and early development (Gall et al. 2011).

Evidence of endocrine disruption in wild fish has been observed in many areas. A high prevalence of testicular oocytes, an intersex condition, has been observed in smallmouth bass within the Potomac (Blazer et al. 2007; Blazer et al. 2010; Iwanowicz et al. 2009) and

64 Susquehanna (Blazer et al. 2014) river basins of the Chesapeake Bay watershed in the eastern

65 United States. Throughout North America, intersex gonads have been found in black bass species including smallmouth bass (Micropterus dolomieu) and largemouth bass (Micropterus

67 salmoides) (Abdel-Moneim et al. 2015; Blazer et al. 2018; Grieshaber et al. 2018; Hinck et al.

68 2009; Iwanowicz et al. 2016; Kellock et al. 2014; Yonkos et al. 2014). The individual chemicals,

69 complex mixtures of chemical compounds and/or other environmental stressors contributing to

70 the development of intersex in specific areas are not yet fully understood. A significant positive

71 correlation was observed between the incidence of intersex and the concentration of Atrazine

72 (ATR) in the water during monitoring of the Potomac river basin at six sites in Maryland, 
73 Virginia, and West Virginia during the spring (Kolpin et al. 2013). This observation highlighted

74 ATR as a contaminant of interest for further investigation into its potential role as an estrogenic 75 endocrine disrupting contaminant (EDC) in the Chesapeake Bay Watershed.

76 Atrazine has been implicated in both reproductive dysfunction in adults and alterations

77 during early development in fish, as well as in other vertebrates (Wirbisky \& Freeman 2015).

78 Adult exposures to atrazine impaired reproduction in medaka (Oryzias latipes) (Papoulias et al.

79 2014) and fathead minnow (Pimephales promelas) (Tillitt et al. 2010). However, the molecular

80 mechanism of endocrine disruption by atrazine remains unclear and appears distinct from the

81 mechanism of estrogenic EDCs (Richter et al. 2016). Atrazine does not directly activate the

82 estrogen receptor, but has been hypothesized to induce expression of cytochrome P450, family

83 19, subfamily A, polypeptide la (cyp19ala, previously aromatase) through inhibition of

84 phosphodiesterase; activation of nuclear receptor subfamily 5, group A, member 1a (Nr5a1a); or

85 alterations in miRNA expression (Sanderson et al. 2001; Roberge et al. 2004; Suzawa \&

86 Ingraham 2008; Wang et al. 2019). Early life stage exposures to atrazine have been reported to

87 alter sex ratios (Suzawa \& Ingraham 2008; Wang et al. 2019).

88 Exposure to estrogenic compounds, including the pharmaceutical estrogen $17 \alpha-$

89 ethinylestradiol (EE2), has been shown to induce intersex in certain fish species (Abdelmoneim

90 et al. 2019). There have been many studies evaluating the effects of EE2 on various fish species

91 at different life stages, especially the model species zebrafish (Danio rerio), medaka, and fathead

92 minnow. However, the exact mechanism causing development of intersex gonads has not been

93 identified and there is a particular data gap in this area for black bass. This early life stage

94 evaluation has not been done in a laboratory setting in black bass species, which are

95 economically important sport fish. Identifying estrogen-specific responses in early life stage 
96 largemouth bass can provide a baseline to build on when identifying mechanisms of action, as

97 estrogens have been shown to have additive effects (Brian et al. 2005).

To evaluate the role of atrazine as an EDC and the role of estrogenic EDCs in intersex,

99 largemouth bass fry were exposed to a range of concentrations of ATR or EE2 during sexual differentiation. To our knowledge this study is the first to measure effects of laboratory ATR and

EE2 exposure in early life stage LMB. The objectives of this study were to: monitor the growth

of LMB and development of the gonads through histological examinations; identify differences

in gene regulation associated with ATR and EE2 exposure; and develop testable hypotheses for

potential biochemical pathways and cellular mechanisms leading to altered gonad development,

the condition of intersex, and ultimately impairment of reproductive function in largemouth bass.

The focus of this manuscript is on potential molecular initiating pathways that could lead to

107 altered gonad development and function.

\section{Materials and methods}

\section{Experimental design}

Largemouth bass fry were exposed to solvent control ( $0.0001 \%$ ethanol), $17 \alpha-$

112 ethinylestradiol (EE2, 1 or $10 \mathrm{ng} / \mathrm{L}$ as a model estrogen control), or atrazine (ATR, 1, 10, or 100

$113 \mu \mathrm{g} / \mathrm{L}$ ) starting at 7 days post spawn (dps). Exposures continued to $80 \mathrm{dps}$, during early gonadal

114 and sexual differentiation. Each treatment was conducted in quadruplicate $(n=4)$, for a total of 24

115 exposure tanks (6 treatments x 4 replicates). Fry/juveniles were sampled at 17, 33, and 80 dps.

116 Each tank began with approximately 500 viable fry at $7 \mathrm{dps}$. At the first two time points, 20 fish

117 per tank were collected for histological examination of gonadal development. At 80 dps 140 fish

118 per treatment (35 fish per tank) were sampled to assess growth, sex identification. Of those fish 
119 sampled at $80 \mathrm{dps}$, gonads of 20 fish per treatment ( 5 fish per tank) were removed for

120 histological sex identification and gene expression analysis. Four treatments were chosen for

121 gene expression analysis: solvent control, low EE2 (1 ng/L), and low and high ATR (1 and 100

$122 \mu \mathrm{g} / \mathrm{L}$ ). Four fish were randomly selected per treatment per sex (4 fish $\mathrm{x} 4$ treatments $\mathrm{x} 2$ sexes)

123 for a total of 32 samples analyzed by RNAseq.

124 All exposure, sample processing, and data analysis was conducted at the U.S. Geological

125 Survey Columbia Environmental Research Center (CERC, Columbia MO, USA) unless

126 otherwise stated. This study was in compliance with all applicable sections of the Final Rules of

127 the Animal Welfare Act regulations (9 CFR) and with all CERC Institutional Animal Care and

128 Use Committee guidelines for the humane treatment of the test organisms during culture and 129 experimentation.

\section{Spawning, egg collection, feeding, and animal care}

The original broodstock of virgin largemouth bass were obtained from the U.S. Fish and

Wildlife Service's Genoa National Fish Hatchery, Genoa, WI. Eggs for the current study were collected from second generation broodstock reared at CERC. Approximately 12-18 sexually mature largemouth bass (6-9 from each sex) were spawned in a 0.2 acre pond containing $45 \mathrm{~cm} \mathrm{x}$ $80 \mathrm{~cm}$ spawning mats placed in shallow near-shore water. Mats with freshly deposited eggs were collected daily, brought into the laboratory and treated with sodium sulfite $(0.015 \%$ solution) for 3-5 minutes to release the eggs from the mats. The eggs were then placed in modified

MacDonald egg incubation tubes and rolled at a temperature no more than $1{ }^{\circ} \mathrm{C}$ from the pond 
142 egg incubation rack until hatch. Hatched fry were collected in mixed cultures and maintained at

143 temperature $\left(22-24^{\circ} \mathrm{C}\right)$ until placed in the exposure tanks. Upon placement in the exposure tanks,

144 the temperature was acclimated to $22^{\circ} \mathrm{C}$ and maintained there for the remainder of the study

145 period under a 16:8 light:dark photoperiod.

146 Hatched fry were fed a combination of three different food sources over the course of the

147 study. Live freshwater rotifers (Brachionus calyciflorus) were fed in conjunction with live,

148 newly hatched brine shrimp (Artemia sp.) nauplii to satiation three times a day during the first

149 week after initiation of exogenous feeding. After the first week, fish were transitioned off rotifers

150 and offered a combination of live, newly hatched Artemia nauplii three times a day and a dry

151 manufactured diet (Otohime, Reed Mariculture) to satiation twice a day. The manufactured diet

152 was administered to the fish via an automatic feeder to each tank. The manufactured diet was

153 adjusted throughout the study based on growth rates and gape width. Tanks were siphoned clean

154 once every other day to remove uneaten food and waste. Additionally, fish were prophylactically

155 treated in-tank twice a week with 20 parts per million (ppm) Chloramine $\mathrm{T}$ for the first four

156 weeks followed by $10 \mathrm{ppm}$ twice a week for the remainder of the study to prevent bacterial

157 outbreaks from occurring.

158 Well water was used in this study and conditions were maintained within criteria set forth

159 by the American Standards and Testing Materials (American Society for Testing and Materials

160 (ASTM) 2004) for toxicity testing with aquatic organisms. General water quality was expected to

161 be $275 \mathrm{mg} / \mathrm{L}$ hardness, $245 \mathrm{mg} / \mathrm{L}$ alkalinity, $8.3 \mathrm{pH}, 0.0200 \mathrm{mg} / \mathrm{L}$ ammonia. Alkalinity, hardness,

$162 \mathrm{pH}$, gas saturation, and ammonia were monitored weekly. Dissolved oxygen and temperature

163 were measured every other day. Tanks were rectangular glass aquaria with $64 \mathrm{~L}$ capacity, filled

164 to $48 \mathrm{~L}$. Each tank had an overflow outlet into the waterbath and an airstone. The sides of each 
165 tank were covered with contact paper to prevent interactions of fish tank to tank. Volume of

166 water flowing into the tanks was checked weekly.

167

168 Exposure and chemical analysis

169 Exposures were conducted in proportional, flow-through diluters with approximately four

170 tank turnovers per day. Exposure chemical concentrations were confirmed twice weekly for the

171 first two weeks, then weekly for the remainder of the exposures. Atrazine (98\% purity, Fluka,

172 College Park, Georgia, USA) was prepared in stock solutions of $25 \mathrm{mg} / \mathrm{L}$ in CERC well water

173 and stored in amber bottles at $4^{\circ} \mathrm{C}$ prior to use. $17 \alpha$-Ethinylestradiol (Sigma-Aldrich, St. Louis,

174 Missouri, USA) was prepared in a stock solution of $10 \mu \mathrm{g} / \mathrm{mL}$ in ethanol. Working solutions in

175 CERC well water of ATR were prepared for final exposure concentrations of 0 , 1, or $100 \mathrm{ug} / \mathrm{L}$

176 and of EE2 for final exposure concentrations of 1 or $10 \mathrm{ng} / \mathrm{L}$ and solvent concentration of

$1770.0001 \%$ ethanol. Diluters were intermittent-flow exposure systems with Hamilton syringes

178 delivering the test chemicals to replicate exposure chambers. System cycling occurred at a rate of

1796 cycles per hour. The system was equilibrated with the test chemicals for 5 days prior to

180 stocking the fish. At the commencement of the exposure, newly hatched fry ( $7 \mathrm{dps})$ were placed

181 in floating baskets within randomly assigned aquaria for each treatment/replicate combination.

182 Atrazine in the tank water was quantified using enzyme-linked immunosorbant assay (ELISA)

183 kits (Abraxis, Warminister, Pennsylvania, USA) in accordance with manufacturer's protocols.

184 Confirmatory analysis was performed on selected water samples by gas chromatography

185 (Jiménez et al. 1997). Briefly, water samples were extracted using methylene chloride; the

186 extract dried with sodium sulfate and filtered through glass fibers; volume reduced to $0.1 \mathrm{~mL}$ in

187 methyl tertiary butyl ether; and triphenylphosphate (Chem Service Inc., West Chester, 
188 Pennsylvania, USA, $500 \mu \mathrm{g} / \mathrm{mL}$ in MtBE) was added as an instrumental internal standard. The 189 extracts were analyzed by gas chromatographic nitrogen/phosphorus detector (GC/NPD) and 190 quantified by Perkin-Elmers TotalChrom ${ }^{\mathrm{TM}}$ workstation chromatography data software. Quality 191 control samples were analyzed with each sample set and included: ATR-spiked water, matrix 192 (well) water blank, and a procedural blank. Concentrations of EE2 in exposure tank water were 193 monitored using an ELISA kit by Ecologiena, (Tokiwa Chemical Industries Co. Ltd, Japan) 194 according to manufacturer's instructions. Water samples were brought to $\mathrm{pH} 7.0$ prior to filtering 195 through a glass fiber filter. Samples were then extracted and concentrated using C18-solid phase 196 extraction. Extracted samples were added to a 96-well microtiter plate that was coated with 197 polyclonal rabbit anti-EE2 antibodies. Following incubation, a tracer conjugated with 198 horseradish peroxidase was applied. After tracer incubation the plate underwent washing and the 199 addition of a color substrate (3,3',5,5'-tetramethylbenzidine, TMB). After color development a 200 stop solution (sulfuric acid) was added before reading the absorbance at $450 \mathrm{~nm}$. The EE2 201 concentrations were determined by quantifying the absorbance values in relation to the measured 202 values of EE2 calibration standards that had be assayed in the same manner.

\section{Fish collection}

Fish were euthanized with an overdose $(300 \mathrm{mg} / \mathrm{L})$ of MS-222 (Ethyl 3-aminobenzoate 206 methanesulfonate, Sigma-Aldrich), blotted dry, then weight and total length were measured.

207 Midsections were sampled from 30 fish per treatment by removing the head just posterior to the 208 opercular flap and tail was removed just posterior to the anal pore and were preserved (see

209 below) for histological analysis. 
Fish sampled for gene expression analysis had an incision made from anal pore to

211 opercular flap, and a panel of muscle tissue removed to obtain access to the juveniles' gonads.

212 RNAlater (Sigma-Aldrich) was used to immediately preserve the gonads still in the body cavity, 213 and to increase visualization and integrity of the gonad tissue. The gonad was then carefully 214 removed and divided. One lobe was preserved (see below) for histological analysis and sex 215 identification. The second lobe was stored in RNAlater at $4{ }^{\circ} \mathrm{C}$ overnight, then transferred to $21620^{\circ} \mathrm{C}$ until RNA was extracted.

\section{Histological analysis}

219 Two different histological samples were taken at 80 dps: 1) whole, intact midsections or 220 2) individual gonad lobes were extracted. Samples were preserved in Z-fix (Anatech Ltd, Battle Creek, Michigan, USA) or PAXgene tissue fix (PreAnalytix, Hombrechtikon, Switzerland) for 12-16 hours then moved to $70 \%$ ethanol and processed within 3 weeks. Midsections were cut in the center and positioned in the paraffin block so both anterior and posterior directions of the midsection could be visualized. Samples were processed by dehydration and embedded into paraffin (Luna 1968). The midsections were sectioned in $5 \mu \mathrm{m}$ transverse cuts until the gonads were clearly visible. Kidney and swim bladder were used to orient the visualization of the gonad, as the gonads are on the ventral side of the swim bladder in the section of the fish where the hind kidney is clearly visible. Slides were stained with hematoxylin and eosin (Luna 1968). In those fish where gonads were extracted during sampling, RNAlater (ThermoFisher, Waltham, Massachusetts, USA) was added to the open cavity of the fish to give the gonads integrity to be more easily removed. Then gonads were removed with forceps, one lobe was taken for histology and the other was preserved in RNAlater for RNAseq (5 fish per treatment). Individual lobe 
233 samples collected for histological analysis were stored in Paxgene for 12-16 $\mathrm{h}$ and then

234 transferred to $70 \%$ ethanol and processed within 3 weeks. For each individual gonad lobe

235 approximately $20-40$ sagittal $5 \mu \mathrm{m}$ thick sections were taken.

236 The characteristics used to identify female fish were: gonadal tissue had the presence of

237 primary oocytes (POs; round cells with hematoxylin staining around the nucleus that was lighter

238 or stained with eosin, and larger than $25 \mu \mathrm{m}$ in diameter), ovarian tissue was relatively larger

239 than testes (larger than $100 \mu \mathrm{m}$ in diameter) and round in shape, typically with an ovarian cavity

240 present. Fry were identified as female if POs were present in any of the sections. A presumptive

241 male identification was made if only primordial germ cells (PGCs) and no POs were present in

242 the gonad sections. It is assumed these undifferentiated gonads were male because this concurs

243 with expected development of male LMB (Johnston 1951). Due to the lack of testis

244 differentiation at this developmental time point, there is a possibility that these undifferentiated

245 gonads could be ovaries with considerably delayed development. However, due to the likelihood

246 that these were males, those identified as presumptive males will hereafter be referred to as

247 males. In females the extreme anterior and posterior ends of ovaries appeared similar to

248 undifferentiated gonadal tissue, except with no PGCs present. When undifferentiated tissue with

249 no PGCs was sectioned further POs were consistently found, leading to a female identification.

250 Conversely, when undifferentiated gonadal tissue with any PGCs was sectioned through the

251 entire gonad no POs were revealed, leading to a male identification. If only connective tissue

252 was present and no gonadal tissue could be identified, sex identification was deemed

253 inconclusive for that fish.

254

255 RNA extraction, library preparation, and sequencing 
Total RNA was extracted from an individual gonad lobe from each of the selected fish,

257

258

259

260

261

262

263

corresponding to a gonad lobe that was processed for histological sex identification. The extraction was performed using an RNeasy Mini Kit (74104, Qiagen, Hilden, Germany). Briefly, tissue was removed from RNAlater and homogenized in $150 \mu 1$ of lysis buffer using a micro-tube homogenizer and pestle (Fisher). The pestle was rinsed with an additional $200 \mu 1$ of buffer following homogenization ( $350 \mu \mathrm{l}$ total) to assure no sample was lost. Extraction was performed according to manufacturer's instruction, with DNase treatment (Qiagen). RNA was eluted off the extraction column in two $14 \mu$ l elutions ( $28 \mu$ l final volume). Capillary electrophoresis on a QIAXEL instrument (Qiagen) was used to characterize the concentration and quality of the RNA following manufacturer's instructions. Four samples per treatment were chosen for the RNAseq analysis. These samples had RNA integrity scores (RIS) with an average of $7.73+/-0.97$. Concentrations of RNA were normalized for all samples. Library preparation and sequencing was performed by the DNA Core facility at the University of Missouri (Columbia, Missouri, USA). Libraries were prepared by Ultra Low RNA Library Preparation kit (Clontech) following manufacturer's instructions. Transcripts were sequenced in four lanes of a 2x75 NextSeq (Illumina) paired-end read.

\section{Assembly of gonad transcriptome}

Initial read processing and assembly into transcript contigs was performed by the sequencing core. The reads were first trimmed of low-quality base calls and adapter sequence, if present, by the Trimmomatic command (Bolger et al. 2014) in Trinity (Trinity-v2.3.2) with default settings except the 5 bases were not removed from each end. Strand specific paired end settings were used assuming the first read was on the sense (forward) strand and the second read 
279 was on the antisense (reverse) strand. All settings were default including the k-mer size of 25.

280 The initial assembly included 743,843 contigs, which was reduced in number to 103,580 by

281 requiring at least 10 counts summed across all samples and imposing a threshold contig length > $282200 \mathrm{nt}$.

283 Prior to differential expression analysis, contigs were clustered at 95\% with cd-hit-est (Li

$284 \&$ Godzik 2006) to further reduce redundancy in the reference assembly, to 59,261 contigs (N50

285 of 3,545 nt). Assembled and clustered RNA contigs will be referred to as transcripts hereafter.

286 Transcripts were annotated using a BlastX search against all Danio rerio peptides (version

287 GRCz10, NCBI accession number GCF_000002035). A reciprocal search identified 11,916 one-

288 to-one matches at a minimum bit score of 100, for which functional annotations were used in

289 enrichment analysis (see below). Annotated transcripts will be referred to as gene transcripts or

290 expressed genes. The average number of mapped reads was $47.4+/-7.4$ million reads/sample.

291

292 Analysis of differential transcript expression

293 For quantification of transcripts, raw reads were reprocessed using a different workflow

294 than that used for assembly. Reads were trimmed with CLC Genomics Workbench v 9.5

295 (Qiagen) at an error probability of 0.05, allowing a maximum of 2 ambiguous bases and

296 requiring a minimum trimmed length of $50 \mathrm{bp}$. Sequencing adapters were removed using default

297 scoring parameters. Abundance was estimated with kallisto (Bray et al. 2016) using a k-mer size

298 of 31 and with sequence composition bias correction. Note that counts estimated by kallisto are

299 probabilistically adjusted to account for sequence shared among multiple transcripts (as in close

300 paralogs or alternative isoforms), resulting in fractional count values. Counts were rounded to

301 integer values for analysis with edgeR (Robinson et al. 2009).

Peer] reviewing PDF | (2020:01:44926:1:1:NEW 29 Jun 2020) 

response by treatment. Two samples (2-2 and 5-5) were strong outliers by this approach and

304 therefore removed from all further analyses. For each contrast tested, low-abundance transcripts

305

were filtered by requiring at least $2 \mathrm{cpm}$ in at least 3 samples, unless the sample size had been reduced due to the exclusions noted above, in which case at least 2 samples with $\geq 2$ cpm were required. The p-value for each transcript was calculated using the "exactTest" function in edgeR, based on the normalized and expression-filtered data for each pairwise contrast and adjusted using the Benjamini-Hochberg correction (Benjamini \& Hochberg 1995) to account for false discovery and an adjusted value of 0.05 was considered the threshold of significant differential expression. No minimum fold-change threshold was used. Genes with significantly male-biased and female-biased expression were identified by comparing male and female expression in the controls using the same thresholds.

\section{Functional enrichment analysis}

Three differentially expressed (DE) gene sets of interest were further analyzed in this study: 1) female-biased DE genes (female expression significantly greater than male) that were also differentially expressed in response to $100 \mu \mathrm{g}$ ATR/L and $1 \mathrm{ng} 17 \alpha$-ethinylestradiol/L treatments in males; 2) DE genes in common among both 1 and $100 \mu \mathrm{g} / \mathrm{L}$ ATR treatments in males; and 3) DE genes in common among both 1 and $100 \mu \mathrm{g} / \mathrm{L}$ ATR treatments in females. For each comparison (gene sets 1,2, and 3; see section 'GO analysis'), enrichment of ontologies and pathway associations among DE genes was evaluated with go-seq (Young et al. 2010), using only the annotations associated with transcripts with one-to-one matches to D. rerio. Go-Slim gene ontology annotations for the parent Ensembl (Hubbard et al. 2002) gene ID of each 
325 matched D. rerio protein were downloaded from BioMart (Smedley et al. 2009) on 01/10/2017.

326 NCBI gene IDs corresponding to each Ensembl gene were downloaded from the public ftp site 327 on $01 / 18 / 2017$.

328

329

330

331

332

333

334

335

336

337

338

339

340

341

342

343

344

345

346

\section{Statistical Analysis}

Statistical analysis of physiological endpoints was performed using JMP 13.1.0 (SAS, Cary NC) with significance set at $5 \%(\mathrm{p}<0.05)$ for all comparisons. Survival, weight, and length were analyzed using analysis of variance (ANOVA) followed by Dunnett's post hoc test to identify treatments that differed significantly from the solvent control. Sex ratios were compared across treatments using a chi-square test.

\section{Results}

\section{Exposure, mortality, growth, and sex identification}

\section{Chemical Exposure}

Concentrations of ATR during the course of the exposure averaged $0.91( \pm 0.06), 9.87( \pm$ $0.68)$, and $105.09( \pm 8.57) \mu \mathrm{g} \mathrm{ATR} / \mathrm{L}$ corresponding to nominal concentrations of 1,10 , and 100 $\mu \mathrm{g}$ ATR/L, respectively. Concentrations of EE2 averaged $0.84( \pm 0.04)$ and $7.34( \pm 0.46) \mathrm{ng}$ EE2/L for corresponding nominal concentrations of 1 and $10 \mathrm{ng}$ EE2/L, respectively. The concentrations in all treatments remained stable throughout the study period (Fig 1). Mortality over the $73 \mathrm{~d}$ study ranged from $52.9 \%$ to $58.4 \%$ among tanks in all treatment groups, and there were no significant differences between treatments (Table 1 and S1). High mortality is expected during early development. We also observed cannibalism among the test 
347 organisms that limited survival, consistent with the ecological role of LMB as voracious

348 piscivores from early in development.

349

350 Gonad development and sex identification

351 Developing gonads in midsections at $17 \mathrm{dps}$ were small and had connective tissue and

352 primordial germ cells (PGCs) (Fig 2, A-B). At 33 dps the gonads were slightly larger and PCGs

353 were observed (Fig 2, C-D). At 80 dps testis tissue remained mainly undifferentiated with the

354 presence of clear PCGs, but no testis-specific characteristics (Fig 2, E-F). Ovarian tissue began

355 to differentiate by $80 \mathrm{dps}$, exhibiting ovarian cavities and primary oocytes in addition to PCGs,

356 and ovaries were much larger than testes in cross-section at this timepoint (Fig 2, G-H).

357 Equal effort was made for sex identification across tanks; the reported $\mathrm{n}$ of each sex for

358 each treatment reflects confident sex identification (Table 1 and S1). To verify consistency in the

359 sex identification protocol, $70 \%$ of samples had one or two additional blind identifications

360 performed, of which $100 \%$ concurred with the original sex identification. The only significant

361 difference in sex ratio from the expected 1:1 female:male was the $10 \mathrm{ng}$ EE2/L treatment, where

362 all fish in each replicate were identified as female, except a single individual from one replicate

363 identified as a male.

364

365 Juvenile growth

366 There were no significant differences in length or weight between treatment groups

367 relative to control when averaged across both sexes. When sex-specific responses were analyzed,

368 female length was significantly greater in the both the 1 and $10 \mathrm{ng}$ EE2/L treatments compared to

369 control (Table 1 and S1). Female weight was significantly increased in the $1 \mathrm{ng}$ EE2/L treatment 
370 group, but not the $10 \mathrm{ng} / \mathrm{L}$ treatment group, compared to control (Table 1 and $\mathrm{S} 1$ ). There were no

371 significant differences between treatment groups for length or weight in males.

372

373 Gene expression analysis

374 Differential expression

375 RNAseq analysis identified 41,565 total transcripts and 28,314 total DE transcripts 376 among all comparisons (BioProject Accession PRJNA485177). Multidimensional scaling of DE

377 transcripts revealed clustering of expression patterns in the $1 \mathrm{ng}$ EE2/L and $100 \mu \mathrm{g}$ ATR/L

378 treated male fish (Fig 3). In females, expression patterns in both atrazine treatments clustered 379 with the controls. Many transcripts were significantly differentially expressed between sexes in 380 the controls, with slightly more male-biased (expression significantly greater in males) than 381 female-biased (expression significantly greater in females; Fig 4). Overall, males exhibited more

382 DE transcripts in response to treatments than females (Fig 4). Few DE transcripts were common 383 between ATR-treated males and females. Most responsive transcripts in males were down384 regulated. In females, most responsive transcripts were upregulated, particularly male-biased 385 transcripts (M>F; Fig 4). In the $1 \mathrm{ng} / \mathrm{L}$ EE2-exposed fish, of those transcripts differentially 386 expressed in gonad (3811 in males, 2120 in females), 721 were identified in both sexes. There 387 was a strong correlation of log-fold changes between males and females among these 721 388 transcripts $\left(\mathrm{R}^{2}=0.92\right)$.

389

390

GO analysis

We developed three gene sets of interest based on intersections among gene sets

392 responsive to different conditions. To test the hypothesis that atrazine exposure had estrogenic 
393 effects on gene expression in male gonad, we examined gene set 1: female-biased DE genes

394 (female expression greater than male in controls) that were also differentially expressed in

395 response to both the $100 \mu \mathrm{g} \mathrm{ATR} / \mathrm{L}$ and $1 \mathrm{ng}$ EE2/L treatments in males. We predicted that more

396 genes with higher expression in ovary would be upregulated in response to both $1 \mathrm{ng}$ EE2/L and

$397100 \mu \mathrm{g}$ ATR/L exposures in males. To investigate atrazine-specific gene expression fingerprints

398 in males, we examined gene set 2: DE genes in common among ATR treatments at both 1 and

$399100 \mu \mathrm{g} / \mathrm{L}$ in males. Finally, to investigate atrazine-specific gene expression fingerprints in

400 females we examined gene set 3: DE genes in common among ATR treatments at both 1 and 100

$401 \mu \mathrm{g} / \mathrm{L}$ in females. Gene ontology (GO) analysis of differentially expressed annotated transcripts

402 (based on Danio rerio annotation) identified several significantly overrepresented terms among

403 the three gene sets of interest tested. Among DE genes responsive to both ATR and EE2

404 treatments in males, there was an overall trend of down-regulation of female-biased genes,

405 contrary to our prediction of a trend for upregulation of genes in this set (Table 2). Two GO

406 terms that were enriched among DE gene sets from males of all treatment groups were ribosome

407 biogenesis and small molecule metabolic process (Table 2). Common GO terms among male and

408 female groups were transport and transmembrane transport. Whereas the male response was

409 typically down-regulation of female-biased genes, the female response was typically

410 upregulation of genes in overrepresented GO terms (Table 2).

411

412 Comparative meta-analysis

413 The comparative meta-analysis identified specific genes of interest that have been shown

414 to respond to both ATR and EE2 exposure (S1 File). This analysis also provided a summary of

415 literature in which those contaminant gene interactions could be found. Of our identified genes 
416 of interest, cytochrome P450, family 11, subfamily A, polypeptide 2 (cyp 1 1a2), steroidogenic

417 acute regulatory protein (star), cytochrome P450, family 1, subfamily A (cypla), DEAD (Asp-

418 Glu-Ala-Asp) box polypeptide 4 (ddx4 (previously vasa)), SAM domain and HD domain 1

419 (samhd1), and wingless-type MMTV integration site family, member $5 b$ (wnt5b) showed

420 differential expression from the control group in at least one treatment group in males (Fig 5).

421

422 Discussion

423 In this study we examined the potential endocrine disrupting effects of a common use

424 herbicide (ATR) and a model estrogen (EE2) in developing largemouth bass. We evaluated both

425 somatic growth and gonad development, as well as global gene expression in isolated developing

426 gonad tissue. Our observation of near-complete sex reversal in the $10 \mathrm{ng}$ EE2/L treatment

427 confirmed that early development was a sensitive window for estrogenic endocrine disruption in

428 LMB and our gene expression results were consistent with the hypothesis that ATR exposure

429 induces some estrogenic responses in the developing gonad.

430

431 Sex reversal, gonad growth, and somatic growth

432

Overall, there was an absence of response to ATR exposure in growth, sex ratio, and

gonad morphology, while EE2 exposure elicited effects on all three. An increase in growth was

434 observed in the EE2-treated female LMB. In the literature there have been both increased and

435 decreased growth observed in fish exposed to EE2. However, low concentration exposures

436 during development have been shown to act like a growth promoter (Chen et al. 2017; Luzio et

437 al. 2015; Örn et al. 2003), as was observed in the current study. All but one fish (94/95) in the 10

438 ng EE2/L treatment were histologically identified as female. Sex reversal resulting from 
439 exposure to high concentrations of EE2 has been observed in other species at exposure 440 concentrations of 3 ng EE2/L and above (Caldwell et al. 2008). The LMB under the current 441 exposure conditions appear to be as sensitive to sex reversal resulting from developmental EE2 442 exposure as the small fish model species zebrafish (Hill \& Janz 2003; Weber et al. 2003) and 443 fathead minnow (van Aerle et al. 2002). LMB appear to be more sensitive to sex reversing 444 effects than what has been observed in three-spined stickleback (Peters et al. 2010), medaka 445 (Scholz \& Gutzeit 2000), and sheepshead minnow (Zillioux et al. 2001). Previous studies have 446 shown that exposure to a concentration of EE2 over a species-specific threshold for sex reversal 447 throughout early development led to organizational changes, and although the sex-reversed 448 phenotype reverted to a phenotype that matched genetic sex in some individuals after a recovery 449 period during adulthood, reproductive dysfunction persisted (Larsen et al. 2009). In wild 450 populations of LMB sex differentiation occurs in spring and summer, which coincides with 451 storm events and typically greater exposures of EDCs in surface water, particularly in areas 452 dominated by agricultural land use (Gall et al. 2011). The mechanisms of sex differentiation in 453 this species have not been characterized well. Since the window of sex differentiation is 454 extremely sensitive to endocrine disruptors in all the vertebrate species tested so far, the EDC 455 effects in LMB germ cells may lead to reproductive impairment later in life, which we did not 456 examine. Such far-reaching effects would be detrimental for LMB populations in the 457 contaminated sites. 458 459 Gene expression alterations 460 Differential expression 
The male LMB gonads were sensitive to estrogenic exposures, as observed by the

462

463

464

465

466

467

468

469

470

471

472

473

474

475

476

477

478

479

480

481

482

483

apparent sex reversal in the $10 \mathrm{ng}$ EE2/L treatment and the overall response in gene expression in the $1 \mathrm{ng}$ EE2/L treatment. We had hypothesized upregulation of female-specific genes in testes among males exposed to EE2. The most differentially expressed genes were those more highly expressed in females, however, most DE genes were downregulated. This counterintuitive result may be caused by negative feedback, leading to downregulation of the female-biased genes in the $1 \mathrm{ng}$ EE2/L treatment.

During this period of gonad development, sex differentiation is just beginning in the males, so effects on gene expression patterns during this stage could lead to alterations in later gonad morphology and possibly function. The earlier stage of gonad differentiation in males compared to females may possibly account for some of the greater responsiveness of gene expression in males, as the fish may be more resistant to the influence of exogenous hormones as gonads become more developed (Blázqueza et al. 1995). The relationship between the observed sex reversal in males and gene expression changes, to intersex formation in adults was not tested in this study. Due to the undifferentiated testes at the sampling time point intersex was not able to be identified. No morphological abnormalities were observed in either treated or controlled fish during the histological analysis and sex identification.

Liver gene expression of vitellogenin $1(\mathrm{vtgl})$, a commonly assayed biomarker of estrogen exposure in fish (Bowman \& Denslow 1999), was not measured in this study, and expression was not observed in gonad. We observed sex-specific expression of three zona pellucida genes, zona pellucida glycoprotein $3 a$, tandem duplicate 2 (zp3a.2), zona pellucida glycoprotein $3 b$ (zp3b), and zona pellucida glycoprotein $3 d$ tandem duplicate 2 (zp3d.2), which are generally estrogen-regulated and expressed in ovary and/or liver in adults (Onichtchouk et al. 
484 2003). Expression of the three zp genes was female-biased, but there were no significant effects 485 of treatment on expression.

486

487 GO analysis

488 Many of the GO terms overrepresented in this analysis were in general involving protein

489 synthesis and transport. Those terms that were found to be common among the sexes had 490 responses in opposite directions, with differentially expressed genes in those categories being 491 largely downregulated in males and upregulated in females exposed to ATR. Downregulation of 492 these processes in developing males may lead to effects later in gonad development.

A GO term of particular interest that was overrepresented for transcripts altered in

494 females in both 1 and $100 \mu \mathrm{g} / \mathrm{L}$ ATR treatments was immune system process. All of the DE 495 genes were upregulated in this term. ATR has been shown to alter immune function in juvenile 496 fish (Kreutz et al. 2012). Estrogen is also known to interfere with immune function in fish 497 (Burgos-Aceves et al. 2016). There are still gaps in our knowledge of the potential effects of 498 these contaminants on juvenile LMB and potential effects on disease susceptibility. There is even 499 less known about how contaminants of interest act in real world mixtures and what role they 500 potentially play in concert to modulate the immune function and disease-resistance of wild 501 populations.

502

503

\section{Comparative meta-analysis}

504 The annotation used for the analysis was Danio rerio, as this is the taxonomically closest 505 species to LMB that has an annotated genome. There are, and will continue to be, limitations in 506 this kind of study until the LMB genome can be fully sequenced and annotated. A reciprocal 
507 best-match criterion between D. rerio and LMB transcripts was used to strengthen annotation

508 inferences, which reduced the number of gene proxies to 11,916 out of approximately 25,549

509 coding genes in D.rerio. The number of genes in LMB is unknown, but the N50 of the assembly

510 was not low by transcriptomic standards $(3,545 \mathrm{bp})$ and only one tissue was analyzed.

511 Nonetheless, partial capture of coding sequences, retention of non-coding sequence, and

512 alternative splicing remain challenges to annotation. We did not attempt to assess alternative

513 splicing with these data, as robust identification of splice variants requires a genomic reference.

514 In developing fish, genes involved in steroidogenesis and gonad development have been

515 shown to either be upregulated or downregulated with EDC exposure depending on the timing,

516 duration, and concentration of the exposure (Leet et al. 2011). In the current study there was a

517 general trend of downregulation of DE genes in males, including cypl la2, star, and $d d x 4$ (Fig

518 5), possibly indicating a negative feedback from EE2 and low concentrations of ATR (Baron et

519 al. 2005; Filby et al. 2007; Leet et al. 2015). The genes of interest identified by the comparative

520 meta-analysis are involved in steroidogenesis, metabolism, and gonad development. The gene

521 products of star and cyp 1 1 a 2 are required for production of all steroid hormones; star encodes a

522 cholesterol transporter which is rate-limiting for steroidogenesis, and cyp l la2 encodes a

523 cholesterol side-chain cleavase (Arukwe 2008). Downregulation of star has been observed in

524 adult human granulosa cells, mediated by an atrazine-induced increase in phosphodiesterase

525 activity (Pogrmic-Majkic et al. 2018). The enzyme encoded by cypla is involved in metabolic

526 breakdown of xenobiotics and steroids (Otte et al. 2017). The RNA helicase encoded by $d d x 4$

527 (previously vasa) is a regulator of translation and is required for primordial germ cell migration

528 (Li et al. 2009). Samhd, an immune-related gene, was also downregulated in the current study. In

529 contrast, a previous study in early life stage zebrafish showed samhd to be upregulated in 
530 response to exposure to ATR (Weber et al. 2013). Wnt5b is an extracellular signaling molecule

531 and morphogen involved in cell differentiation and formation and maintenance of tissues and

532 organs (Yang 2012).

533 However, a few of the DE genes of interest were upregulated in males. Wnt $5 b$ was

534 upregulated in the EE2 treatment, and Cypla was also upregulated in EE2 and high ATR

535 treatment males. Cypla has previously been shown to upregulate in fish where ATR exposure

536 lead to DNA strand breaks and damaged blood cells (Chang et al. 2005).

537

538 Conclusion

539

The early stage in LMB gonad development assessed in the current study was seen to be

540 sensitive to molecular responses to EDCs, and organizational alterations in the form of sex

541 reversal with exposure to a high concentration of a potent estrogen. Exposure to ATR resulted in

542 changes in gene expression, with both similarities and differences compared to pathways

543 activated by estrogen. Exposure to the strong estrogenic EDC EE2 set developing fish on a path

544 to physiological change that was observed across multiple levels of biological organization:

545 changes in gene expression, changes in histology, and changes in morphology. Thus, our results

546 delineate pathways from estrogenic exposures to adverse outcomes in a major sport fish. The

547 role of ATZ in population impairments observed in the field remains unclear. It is possible that

548 the combined impacts of mixtures of contaminants including atrazine lead to population-level

549 effects on reproduction and disease resistance (Berninger et al. 2019). Investigation of effects of

550 mixtures at multiple levels of biological organization may help reveal diagnostic biomarkers of

551 pathways leading to adverse population-level effects. In wild populations early sex

552 differentiation occurs in the spring and summer, which coincides with storm events and typically 
553 higher concentrations of EDCs in surface water, particularly in areas dominated by agricultural

554 land use. To our knowledge this is the first examination of developmental and molecular

555 responses to EDCs in juvenile LMB. This study can serve as an initial piece of the larger picture

556 of the sensitivity of developing bass to contaminants of interest in the Chesapeake Bay.

557 Additional studies are being conducted in adult LMB exposed to mixtures of contaminants of

558 interest. Controlled laboratory exposures with field-relevant sport fish can provide a basis for

559 identification of specific mechanisms of action, determination of effect concentrations, and

560 establishment of cause and effect linkages for contaminants and other stressors that may limit the

561 health and growth of wild populations.

562

\section{Acknowledgements}

564

565

566

567

568

569

570

571

572

573

574

575

576
We are grateful for the assistance of R. Claunch, J. Candrl, and V. Velez (Columbia

Environmental Research Center, US Geological Survey, Columbia, MO). The present study was supported by the US Geological Survey, Contaminants Biology Program, Environmental Health Mission Area. The authors declare no conflicts of interest. Any use of trade, product, or firm names is for descriptive purposes only and does not imply endorsement by the US government.

\section{References}

Abdel-Moneim A, Coulter DP, Mahapatra CT, and Sepulveda MS. 2015. Intersex in fishes and amphibians: population implications, prevalence, mechanisms and molecular biomarkers. Journal of Applied Toxicology. 10.1002/jat.3204

Abdelmoneim A, Abdu A, Chen S, and Sepulveda MS. 2019. Molecular signaling pathways elicited by 17alpha-ethinylestradiol in Japanese medaka male larvae undergoing gonadal differentiation. Aquatic Toxicology 208:187-195. 10.1016/j.aquatox.2019.01.013 
577

578

579

580

581

582

583

584

585

586

587

588

589

590

591

592

593

594

595

596

597

598

599

600

601

602

603

604

605

606

607

608

609

610

611

612

613

American Society for Testing and Materials (ASTM). 2004. Standard guide for conducting acute toxicity tests on test materials with fishes, macroinvertebrates, and amphibians (ASTM E729-96). West Conshohocken, PA: ASTM.

Arukwe A. 2008. Steroidogenic acute regulatory (StAR) protein and cholesterol side-chain cleavage (P450scc)-regulated steroidogenesis as an organ-specific molecular and cellular target for endocrine disrupting chemicals in fish. Cell Biology and Toxicology 24:527540 .

Baron D, Houlgatte R, Fostier A, and Guiguen Y. 2005. Large-scale temporal gene expression profiling during gonadal differentiation and early gametogenesis in rainbow trout. Biology of Reproduction 73:959-966.

Benjamini Y, and Hochberg Y. 1995. Controlling the False Discovery Rate: A Practical and Powerful Approach to Multiple Testing. Journal of the Royal Statistical Society Series B (Methodological) 57:289-300.

Berninger JP, DeMarini DM, Warren SH, Simmons JE, Wilson VS, Conley JM, Armstrong MD, Iwanowicz LR, Kolpin DW, Kuivila KM, Reilly TJ, Romanok KM, Villeneuve DL, and Bradley PM. 2019. Predictive analysis using chemical-gene interaction networks consistent with observed endocrine activity and mutagenicity of U.S. streams. Environmental Science \& Technology 53:8611-8620. 10.1021/acs.est.9b02990

Blazer VS, Iwanowicz DD, Walsh HL, Sperry AJ, Iwanowicz LR, Alvarez DA, Brightbill RA, Smith G, Foreman WT, and Manning R. 2014. Reproductive health indicators of fishes from Pennsylvania watersheds: association with chemicals of emerging concern. Environmental Monitoring and Assessment 186:6471-6491. 10.1007/s10661-014-3868-5

Blazer VS, Iwanowicz LR, Iwanowicz DD, Smith DR, Young JA, Hedrick JD, Foster SW, and Reeser SJ. 2007. Intersex (testicular oocytes) in smallmouth bass from the Potomac River and selected nearby drainages. Journal of Aquatic Animal Health 19:242-253.

Blazer VS, Iwanowicz LR, Starliper CE, Iwanowicz DD, Barbash P, Hedrick JD, Reeser SJ, Mullican JE, Zaugg SD, Burkhardt MR, and Kelble J. 2010. Mortality of centrarchid fishes in the Potomac drainage: Survey results and overview of potential contributing factors. Journal of Aquatic Animal Health 22:190-218. 10.1577/h10-002.1

Blazer VS, Walsh HL, Shaw CH, Iwanowicz LR, Braham RP, and Mazik PM. 2018. Indicators of exposure to estrogenic compounds at Great Lakes Areas of Concern: species and site comparisons. Environmental Monitoring and Assessment 190:577. 10.1007/s10661-0186943-5

Blázqueza M, Piferrer F, Zanuy S, Carrillo M, Donaldson EM. 1995. Development of sex control techniques for European sea bass (Dicentrarchus labrax L.) aquaculture: effects of dietary $17 \alpha$-methyltestosterone prior to sex differentiation. Aquaculture 135:329-342. 10.1016/0044-8486(95)01030-0

Peer] reviewing PDF | (2020:01:44926:1:1:NEW 29 Jun 2020) 
614 Bolger AM, Lohse M, and Usadel B. 2014. Trimmomatic: a flexible trimmer for Illumina

615 sequence data. Bioinformatics 30:2114-2120. 10.1093/bioinformatics/btu170

616

617

618

619

620

621

622

623

624

625

626

627

628

629

630

631

632

633

634

635

636

637

638

639

640

641

642

643

644

645

646

647

648

649

650

Bowman CJ, and Denslow ND. 1999. Development and validation of a species- and genespecific molecular biomarker: Vitellogenin mRNA in largemouth bass (Micropterus salmoides). Ecotoxicology 8:399-416.

Bray NL, Pimentel H, Melsted P, and Pachter L. 2016. Near-optimal probabilistic RNA-seq quantification. Nature Biotechnology 34:525. 10.1038/nbt.3519

Brian JV, Harris CA, Scholze M, Backhaus T, Booy P, Lamoree M, Pojana G, Jonkers N, Runnalls T, Bonfà A, Marcomini A, and Sumpter JP. 2005. Accurate Prediction of the Response of Freshwater Fish to a Mixture of Estrogenic Chemicals. Environmental Health Perspectives 113:721-728. 10.1289/ehp.7598

Burgos-Aceves MA, Cohen A, Smith Y, and Faggio C. 2016. Estrogen regulation of gene expression in the teleost fish immune system. Fish \& Shellfish Immunology 58:42-49. 10.1016/j.fsi.2016.09.006

Caldwell DJ, Mastrocco F, Hutchinson TH, Lange R, Heijerick D, Janssen C, Anderson PD, and Sumpter JP. 2008. Derivation of an aquatic predicted no-effect concentration for the synthetic hormone, 17 alpha-ethinyl estradiol. Environ Sci Technol 42:7046-7054. $10.1021 /$ es $800633 q$

Chang LW, Toth GP, Gordon DA, Graham DW, Meier JR, Knapp CW, deNoyelles FJ, Jr. , Campbell S, and Lattier DL. 2005. Responses of molecular indicators of exposure in mesocosms: common carp (Cyprinus carpio) exposed to the herbicides alachlor and atrazine. Environmental Toxicology and Chemistry 24:190-197.

Chen Y, Li M, Yuan L, Xie Y, Li B, Xu W, Meng F, and Wang R. 2017. Growth, blood health, antioxidant status and immune response in juvenile yellow catfish Pelteobagrus fulvidraco exposed to $\alpha$-ethinylestradiol (EE2). Fish \& Shellfish Immunology 69:1-5. 10.1016/j.fsi.2017.08.003

Filby AL, Thorpe KL, Maack G, and Tyler CR. 2007. Gene expression profiles revealing the mechanisms of anti-androgen- and estrogen-induced feminization in fish. Aquatic Toxicology 81:219-231.

Gall HE, Sassman SA, Lee LS, and Jafvert CT. 2011. Hormone discharges from a midwest tiledrained agroecosystem receiving animal wastes. Environmental Science \& Technology 45:8755-8764. 10.1021/es2011435

Grieshaber CA, Penland TN, Kwak TJ, Cope WG, Heise RJ, Law JM, Shea D, Aday DD, Rice JA, and Kullman SW. 2018. Relation of contaminants to fish intersex in riverine sport fishes. Science of the Total Environment 643:73-89. 10.1016/j.scitotenv.2018.06.071

Hill RL, Jr., and Janz DM. 2003. Developmental estrogenic exposure in zebrafish (Danio rerio): I. Effects on sex ratio and breeding success. Aquatic Toxicology 63:417-429.

Peer] reviewing PDF | (2020:01:44926:1:1:NEW 29 Jun 2020) 
651

652

653

654

655

656

657

658

659

660

661

662

663

664

665

666

667

668

669

670

671

672

673

674

675

676

677

678

679

680

681

682

683

684

685

686

687

688

689
Hinck JE, Blazer VS, Schmitt CJ, Papoulias DM, and Tillitt DE. 2009. Widespread occurrence of intersex in black basses (Micropterus spp.) from U.S. rivers, 1995-2004. Aquatic Toxicology 95:60-70.

Hubbard T, Barker D, Birney E, Cameron G, Chen Y, Clark L, Cox T, Cuff J, Curwen V, Down T, Durbin R, Eyras E, Gilbert J, Hammond M, Huminiecki L, Kasprzyk A, Lehvaslaiho H, Lijnzaad P, Melsopp C, Mongin E, Pettett R, Pocock M, Potter S, Rust A, Schmidt E, Searle S, Slater G, Smith J, Spooner W, Stabenau A, Stalker J, Stupka E, Ureta-Vidal A, Vastrik I, and Clamp M. 2002. The Ensembl genome database project. Nucleic Acids Research 30:38-41. 10.1093/nar/30.1.38

Iwanowicz LR, Blazer VS, Guy CP, Pinkney AE, Mullican JE, and Alvarez DA. 2009. Reproductive health of bass in the Potomac, USA, drainage: Part 1. Exploring the effects of proximity to wastewater treatment plant discharge. Environmental Toxicology and Chemistry 28:1072-1083.

Iwanowicz LR, Blazer VS, Pinkney AE, Guy CP, Major AM, Munney K, Mierzykowski S, Lingenfelser S, Secord A, Patnode K, Kubiak TJ, Stern C, Hahn CM, Iwanowicz DD, Walsh HL, and Sperry A. 2016. Evidence of estrogenic endocrine disruption in smallmouth and largemouth bass inhabiting Northeast U.S. national wildlife refuge waters: A reconnaissance study. Ecotoxicology and Environmental Safety 124:50-59. 10.1016/j.ecoenv.2015.09.035

Jiménez JJ, Bernal JL, del Nozal MJ, and Rivera JM. 1997. Determination of pesticide residues in waters from small loughs by solid-phase extraction and combined use of gas chromatography with electron-capture and nitrogen-phosphorus detection and highperformance liquid chromatography with diode array detection. Journal of Chromatography A 778:289-300.

Johnston PM. 1951. The embryonic history of the germ cells of the largemouth black bass, Micropterus salmoides salmoides (Lacépède). Journal of Morphology 88:471-542. 10.1002/jmor.1050880304

Kellock KA, Trushel BE, Ely PC, Jennings CA, and Bringolf RB. 2014. Survey of intersex largemouth bass from impoundments in Georgia USA. Transactions of the American Fisheries Society 143:565-572. 10.1080/00028487.2013.824922

Kolpin DW, Blazer VS, Gray JL, Focazio MJ, Young JA, Alvarez DA, Iwanowicz LR, Foreman WT, Furlong ET, Speiran GK, Zaugg SD, Hubbard LE, Meyer MT, Sandstrom MW, and Barber LB. 2013. Chemical contaminants in water and sediment near fish nesting sites in the Potomac River basin: Determining potential exposures to smallmouth bass (Micropterus dolomieu). Science of the Total Environment 443:700-716. 10.1016/j.scitotenv.2012.09.063

Kreutz LC, Barcellos LJ, dos Santos ED, Pivato M, and Zanatta R. 2012. Innate immune response of silver catfish (Rhamdia quelen) exposed to atrazine. Fish and Shellfish Immunology 33:1055-1059. 10.1016/j.fsi.2012.08.006 
690 Larsen MG, Bilberg K, and Baatrup E. 2009. Reversibility of estrogenic sex changes in zebrafish

691

692

693

694

695

696

697

698

699

700

701

702

703

704

705

706

707

708

709

710

711

712

713

714

715

716

717

718

719

720

721

722

723

724

725 (Danio rerio). Environmental Toxicology and Chemistry 28:1783-1785. 10.1897/08-563.1

Leet JK, Gall HE, and Sepulveda MS. 2011. A review of studies on androgen and estrogen exposure in fish early life stages: effects on gene and hormonal control of sexual differentiation. Journal of Applied Toxicology 31:379-398. 10.1002/jat.1682

Leet JK, Sassman S, Amberg JJ, Olmstead AW, Lee LS, Ankley GT, and Sepúlveda MS. 2015. Environmental hormones and their impacts on sex differentiation in fathead minnows. Aquatic Toxicology 158:98-107. 10.1016/j.aquatox.2014.10.022

Li M, Hong N, Xu H, Yi M, Li C, Gui J, and Hong Y. 2009. Medaka vasa is required for migration but not survival of primordial germ cells. Mechanisms of Development 126:366-381. 10.1016/j.mod.2009.02.004

Li W, and Godzik A. 2006. Cd-hit: a fast program for clustering and comparing large sets of protein or nucleotide sequences. Bioinformatics 22:1658-1659. 10.1093/bioinformatics/btl158

Luna LG. 1968. Manual of histologic staining methods of the armed forces institute of pathology, 3rd edn. McGraw- Hill, New York, NY. New York, NY: McGraw- Hill.

Luzio A, Monteiro SM, Garcia-Santos S, Rocha E, Fontainhas-Fernandes AA, and Coimbra AM. 2015. Zebrafish sex differentiation and gonad development after exposure to 17alphaethinylestradiol, fadrozole and their binary mixture: A stereological study. Aquatic Toxicology 166:83-95. 10.1016/j.aquatox.2015.07.015

Örn S, Holbech H, Madsen TH, Norrgren L, and Petersen GI. 2003. Gonad development and vitellogenin production in zebrafish (Danio rerio) exposed to ethinylestradiol and methyltestosterone. Aquatic Toxicology 65:397-411.

Otte JC, Schultz B, Fruth D, Fabian E, van Ravenzwaay B, Hidding B, and Salinas ER. 2017. Intrinsic xenobiotic metabolizing enzyme activities in early life stages of Zebrafish (Danio rerio). Toxicological Sciences 159:86-93. 10.1093/toxsci/kfx116

Papoulias DM, Tillitt DE, Talykina MG, Whyte JJ, and Richter CA. 2014. Atrazine reduces reproduction in Japanese medaka (Oryzias latipes). Aquatic Toxicology 154:230-239. 10.1016/j.aquatox.2014.05.022

Peters RE, Courtenay SC, Hewitt LM, and MacLatchy DL. 2010. Effects of 17alphaethynylestradiol on early-life development, sex differentiation and vitellogenin induction in mummichog (Fundulus heteroclitus). Marine Environmental Research 69:178-186. 10.1016/j.marenvres.2009.10.002

Pogrmic-Majkic K, Samardzija D, Stojkov-Mimic N, Vukosavljevic J, Trninic-Pjevic A, Kopitovic V, and Andric N. 2018. Atrazine suppresses FSH-induced steroidogenesis and LH-dependent expression of ovulatory genes through PDE-cAMP signaling pathway in 
726

727

728

729

730

731

732

733

734

735

736

737

738

739

740

741

742

743

744

745

746

747

748

749

750

751

752

753

754

755

756

757

758

759

760

761

human cumulus granulosa cells. Molecular and Cellular Endocrinology 461:79-88. 10.1016/j.mce.2017.08.015

Richter CA, Papoulias DM, Whyte JJ, and Tillitt DE. 2016. Evaluation of potential mechanisms of atrazine-induced reproductive impairment in fathead minnow (Pimephales promelas) and Japanese medaka (Oryzias latipes). Environmental Toxicology and Chemistry 35:2230-2238. 10.1002/etc.3376

Roberge M, Hakk H, and Larsen G. 2004. Atrazine is a competitive inhibitor of phosphodiesterase but does not affect the estrogen receptor. Toxicology Letters 154:6168.

Robinson MD, McCarthy DJ, and Smyth GK. 2009. edgeR: a Bioconductor package for differential expression analysis of digital gene expression data. Bioinformatics 26:139140. 10.1093/bioinformatics/btp616

Sanderson JT, Letcher RJ, Heneweer M, Giesy JP, and van den Berg M. 2001. Effects of chloros-triazine herbicides and metabolites on aromatase activity in various human cell lines and on vitellogenin production in male carp hepatocytes. Environmental Health Perspectives 109:1027-1031.

Scholz S, and Gutzeit HO. 2000. 17-a-ethinylestradiol affects reproduction, sexual differentiation and aromatase gene expression of the medaka (Oryzias latipes). Aquatic Toxicology 50:363-373.

Smedley D, Haider S, Ballester B, Holland R, London D, Thorisson G, and Kasprzyk A. 2009. BioMart - biological queries made easy. BMC Genomics 10:22. 10.1186/1471-2164-1022

Suzawa M, and Ingraham HA. 2008. The herbicide atrazine activates endocrine gene networks via non-steroidal NR5A nuclear receptors in fish and mammalian cells. PLoS ONE 3:e2117.

Tillitt DE, Papoulias DM, Whyte JJ, and Richter CA. 2010. Atrazine reduces reproduction in fathead minnow (Pimephales promelas). Aquatic Toxicology 99:149-159. 10.1016/j.aquatox.2010.04.011

van Aerle R, Pounds N, Hutchinson TH, Maddix S, and Tyler CR. 2002. Window of sensitivity for the estrogenic effects of ethinylestradiol in early life-stages of fathead minnow, Pimephales promelas. Ecotoxicology 11:423-434. 10.1023/a:1021053217513

Wang F, Yang QW, Zhao WJ, Du QY, and Chang ZJ. 2019. Effects of short-time exposure to atrazine on miRNA expression profiles in the gonad of common carp (Cyprinus carpio). BMC Genomics 20:587. 10.1186/s12864-019-5896-6

Weber GJ, Sepúlveda MS, Peterson SM, Lewis SS, and Freeman JL. 2013. Transcriptome alterations following developmental atrazine exposure in zebrafish are associated with

Peer] reviewing PDF | (2020:01:44926:1:1:NEW 29 Jun 2020) 
762

763

764

765

766

767

768

769

770

771

772

773 774

775

776

777

778

779

780

disruption of neuroendocrine and reproductive system function, cell cycle, and carcinogenesis. Toxicological Sciences 132:458-466. 10.1093/toxsci/kft017

Weber LP, Hill RL, Jr. , and Janz DM. 2003. Developmental estrogenic exposure in zebrafish (Danio rerio): II. Histological evaluation of gametogenesis and organ toxicity. Aquatic Toxicology 63:431-446.

Wirbisky S, and Freeman J. 2015. Atrazine exposure and reproductive dysfunction through the hypothalamus-pituitary-gonadal (HPG) axis. Toxics 3:414-450. 10.3390/toxics3040414

Yang Y. 2012. Wnt signaling in development and disease. Cell \& Bioscience 2:14.

Yonkos LT, Friedel EA, and Fisher DJ. 2014. Intersex (testicular oocytes) in largemouth bass (Micropterus salmoides) on the Delmarva Peninsula, USA. Environmental Toxicology and Chemistry 33:1163-1169. 10.1002/etc.2544

Young MD, Wakefield MJ, Smyth GK, and Oshlack A. 2010. Gene ontology analysis for RNAseq: accounting for selection bias. Genome Biology 11:R14. 10.1186/gb-2010-11-2-r14

Zillioux EJ, Johnson IC, Kiparissis Y, Metcalfe CD, Wheat JV, Ward SG, and Liu H. 2001. The sheepshead minnow as an in vivo model for endocrine disruption in marine teleosts: A partial life-cycle test with 17a-ethynylestradiol. Environmental Toxicology and Chemistry 20:1968-1978.

PeerJ reviewing PDF | (2020:01:44926:1:1:NEW 29 Jun 2020) 


\section{Figure 1}

Chemical concentration data.

Concentrations of atrazine (ATR, [A]) and 17 $\alpha$-ethinylestradiol (EE2, [B]) at various time points during the 70 day flow-through exposure. All replicates measured at each time $(n=4)$ for all treatments, except for the solvent control ( $n=1$ for ATR, $n=2$ for EE2). Error bars represent standard deviation. 


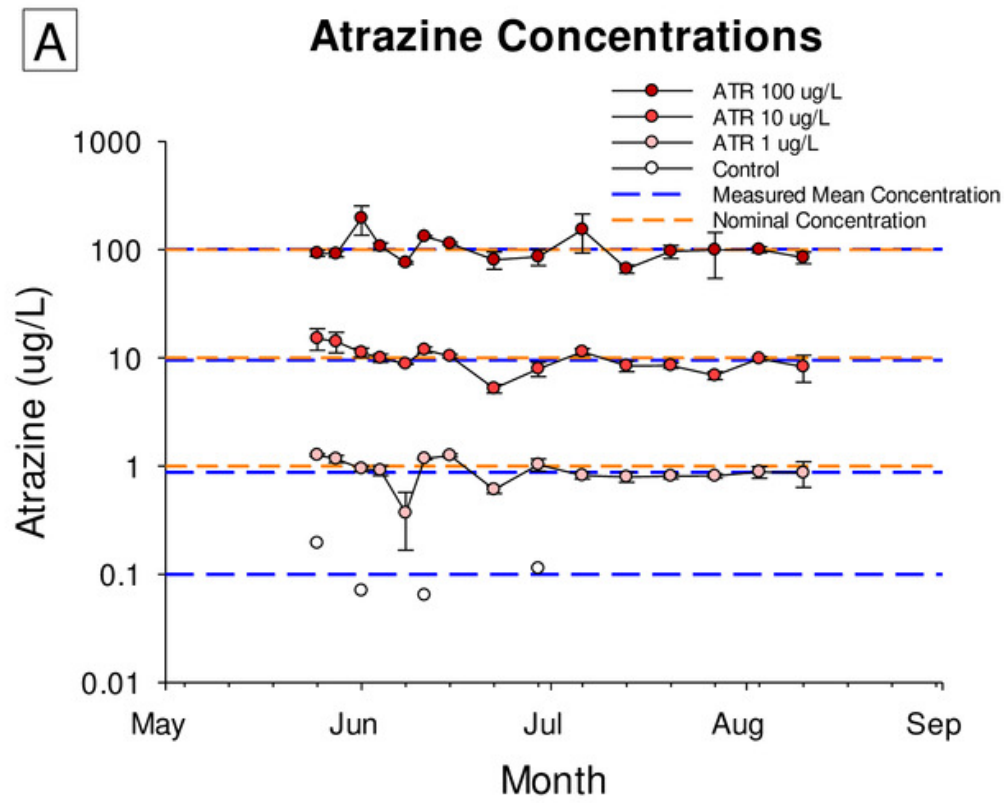

B Ethinyl estradiol Concentrations

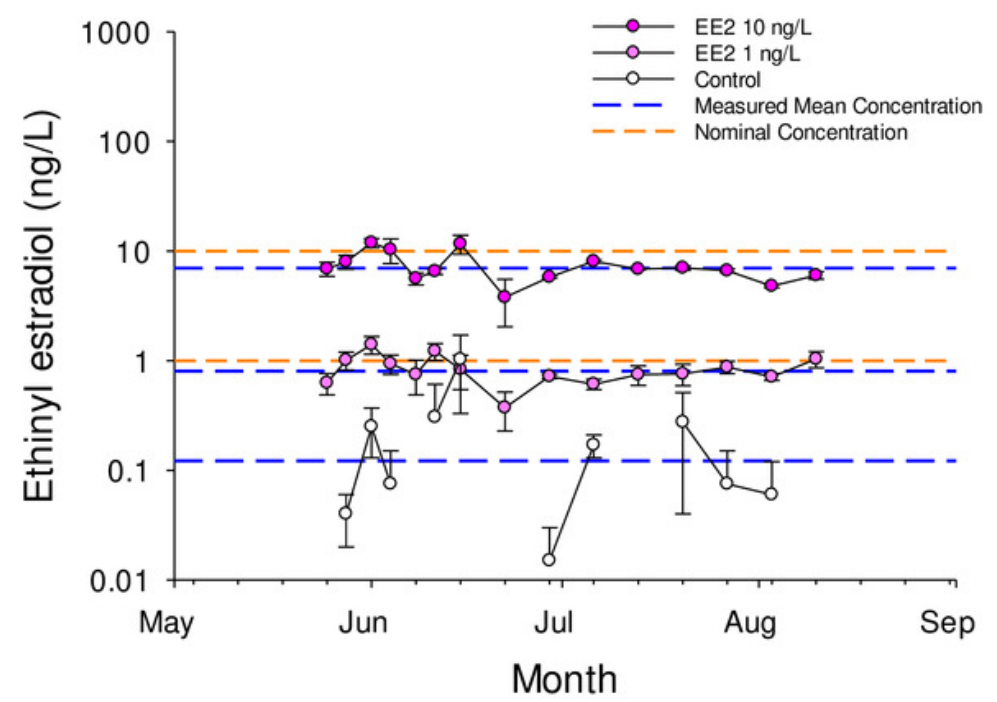




\section{Figure 2}

Gonad development.

Example of gonad development from the control treatment at 17 days post-spawn (dps) at 100X (A) and 400X (B) magnification, $33 \mathrm{dps}$ at 40X (C) and 400X (D) magnification, $80 \mathrm{dps}$ male at 40X (E) and 400X (F) magnification, and $80 \mathrm{dps}$ female at $40 \mathrm{X}(\mathrm{G})$ and $100 \mathrm{X}(\mathrm{H})$ magnification. The bar in the upper right of each panel equals $50 \mu \mathrm{m}$. PGC, primordial germ cell; PO, primary oocyte; OC, ovarian cavity. 
Time 1 (17 dps)

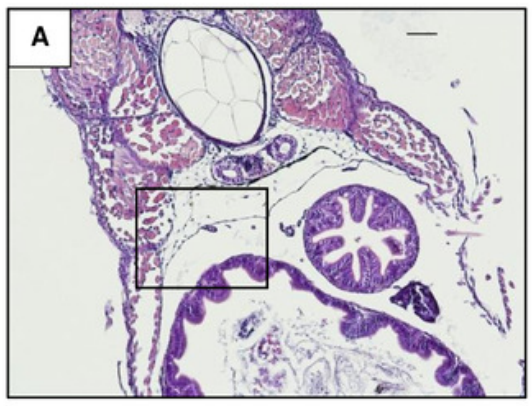

Time 2 (33 dps)

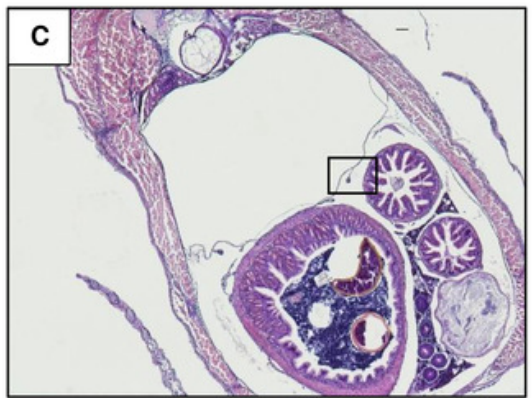

Time 3 (80 dps) Male

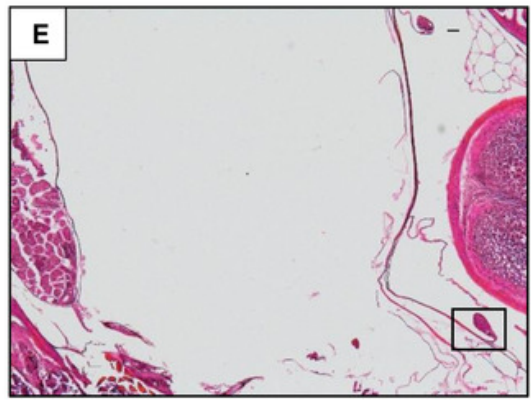

Time 3 (80 dps) Female

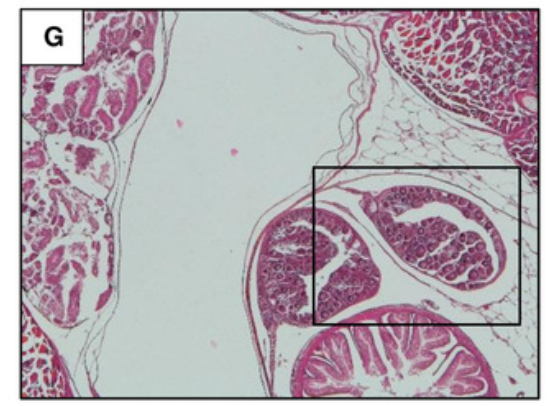

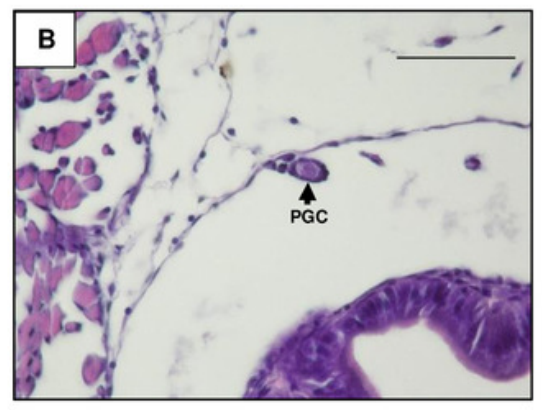
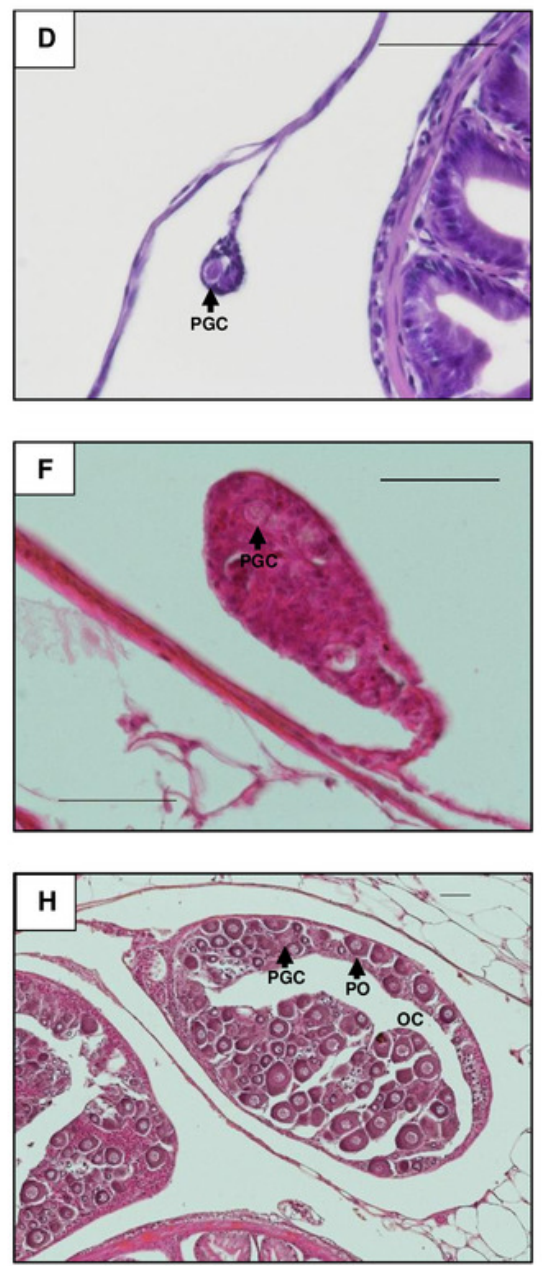
Figure 3

Multidimensional scaling (MDS) with normalized counts.

MDS of transcript expression patterns in juvenile largemouth bass gonads. Individual samples are represented by triangles (males) or circles (females). 1-ATR $=1 \mu \mathrm{g} / \mathrm{L}$ Atrazine; 100-ATR $=$ $100 \mu \mathrm{g} / \mathrm{L}$ Atrazine; 1-EE2 = $1 \mathrm{ng} / \mathrm{L} 17 \alpha$-ethinylestradiol. 


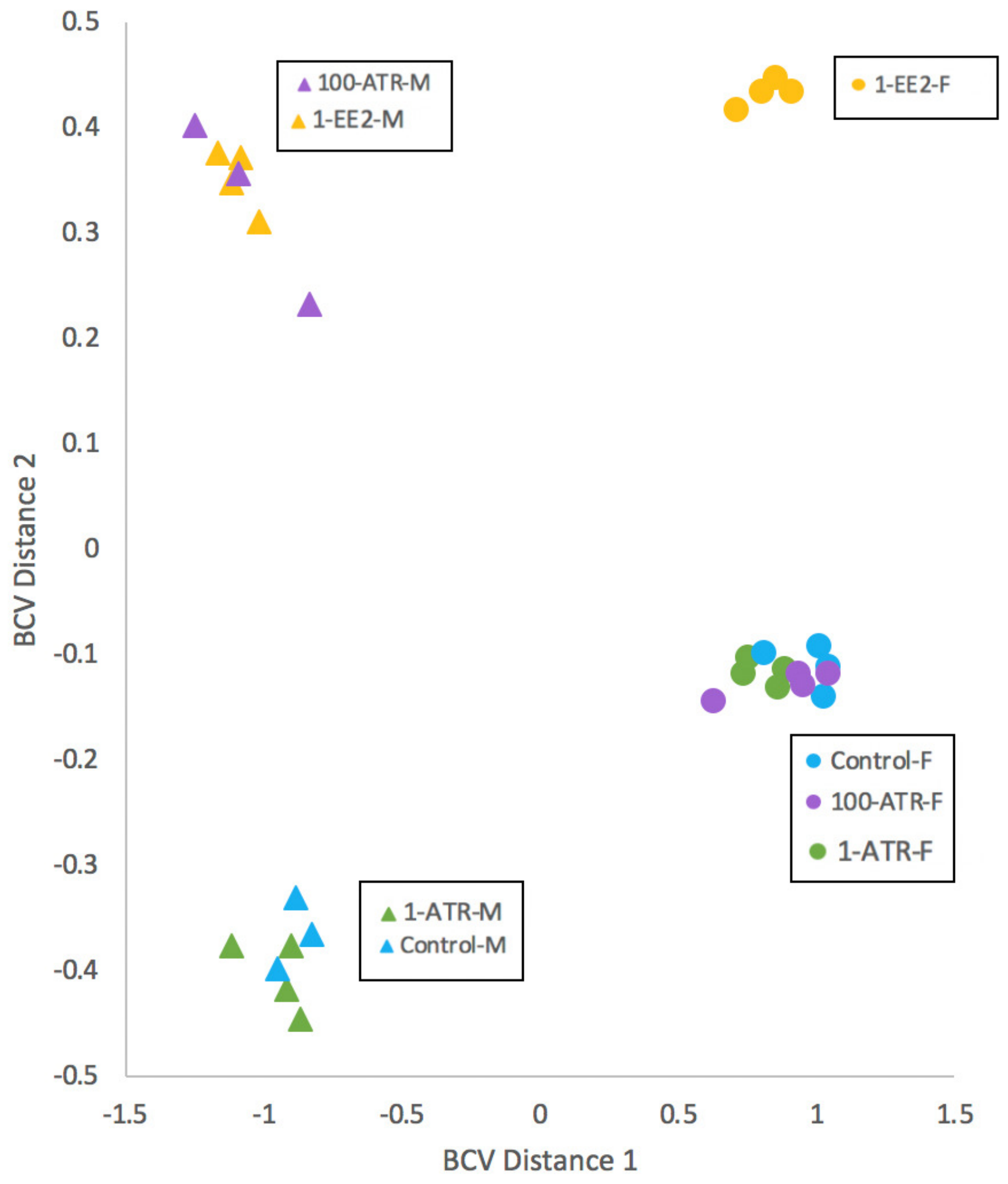




\section{Figure 4}

Comparison of differentially expressed transcripts in each test group by sex.

Diagram of overlapping sets of differentially expressed (DE) transcripts that were common between sample groups and treatments. $M=$ male, $F=$ female; $F>M=$ female-biased transcripts that had significantly greater expression in females than males in the controls; $\mathrm{M}>\mathrm{F}=$ male-biased transcripts that had significantly greater expression in males than females in the controls; 1-ATR $=1 \mu \mathrm{g} / \mathrm{L}$ Atrazine treatment; 100-ATR $=100 \mu \mathrm{g} / \mathrm{L}$ Atrazine treatment; 1-EE2 $=1 \mathrm{ng} / \mathrm{L} 17 \alpha$-ethinylestradiol treatment. DE genes that did not have uniform regulation responses between treatments were not represented in the number of upand downregulated genes in bar graphs $\mathrm{A}-\mathrm{H}$, but were included in the total number of $\mathrm{DE}$ genes in the Venn diagrams. There are 28,314 total DE transcripts. Conditions used to frame the three gene ontology $(\mathrm{GO})$ queries are highlighted. 

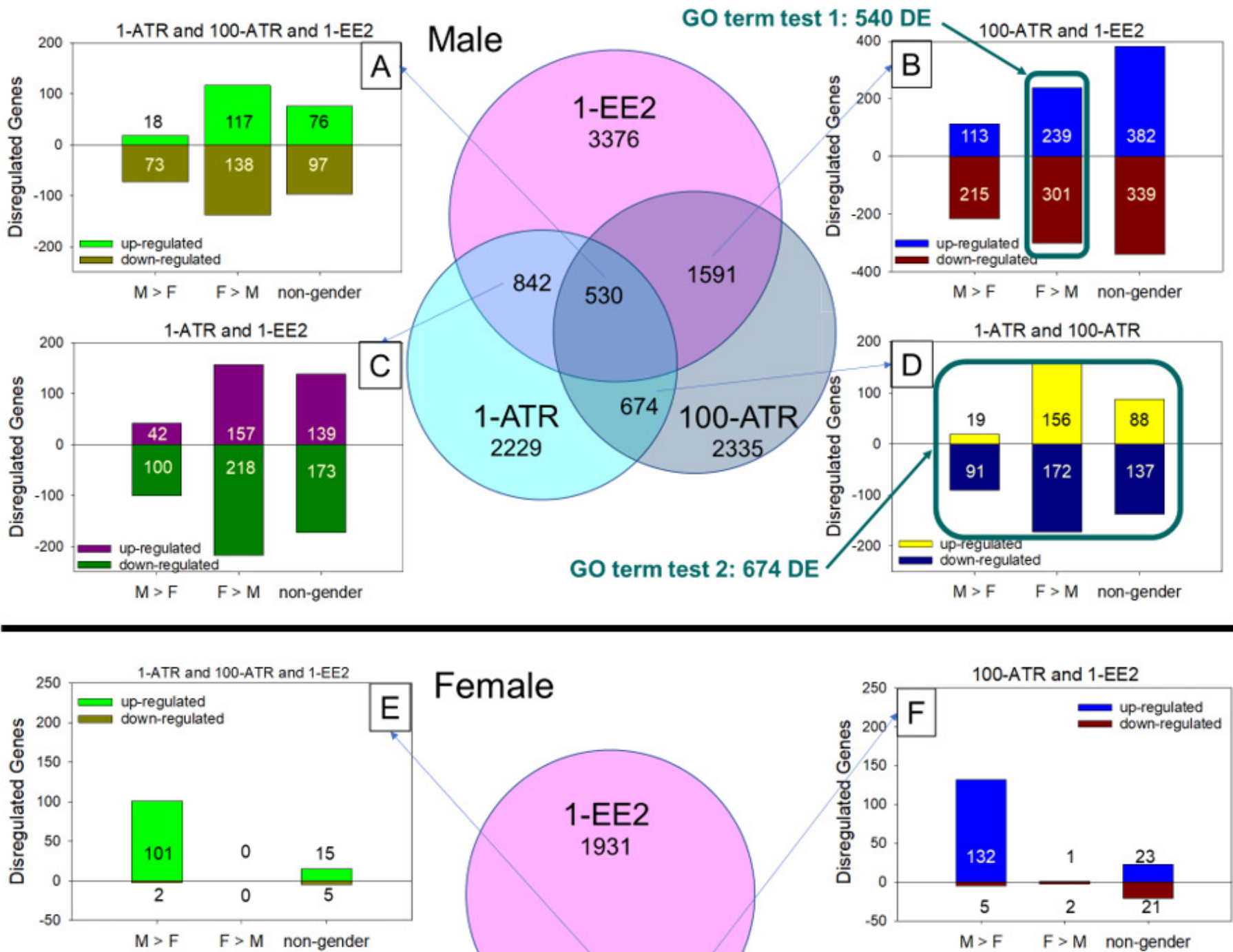

\section{Female}
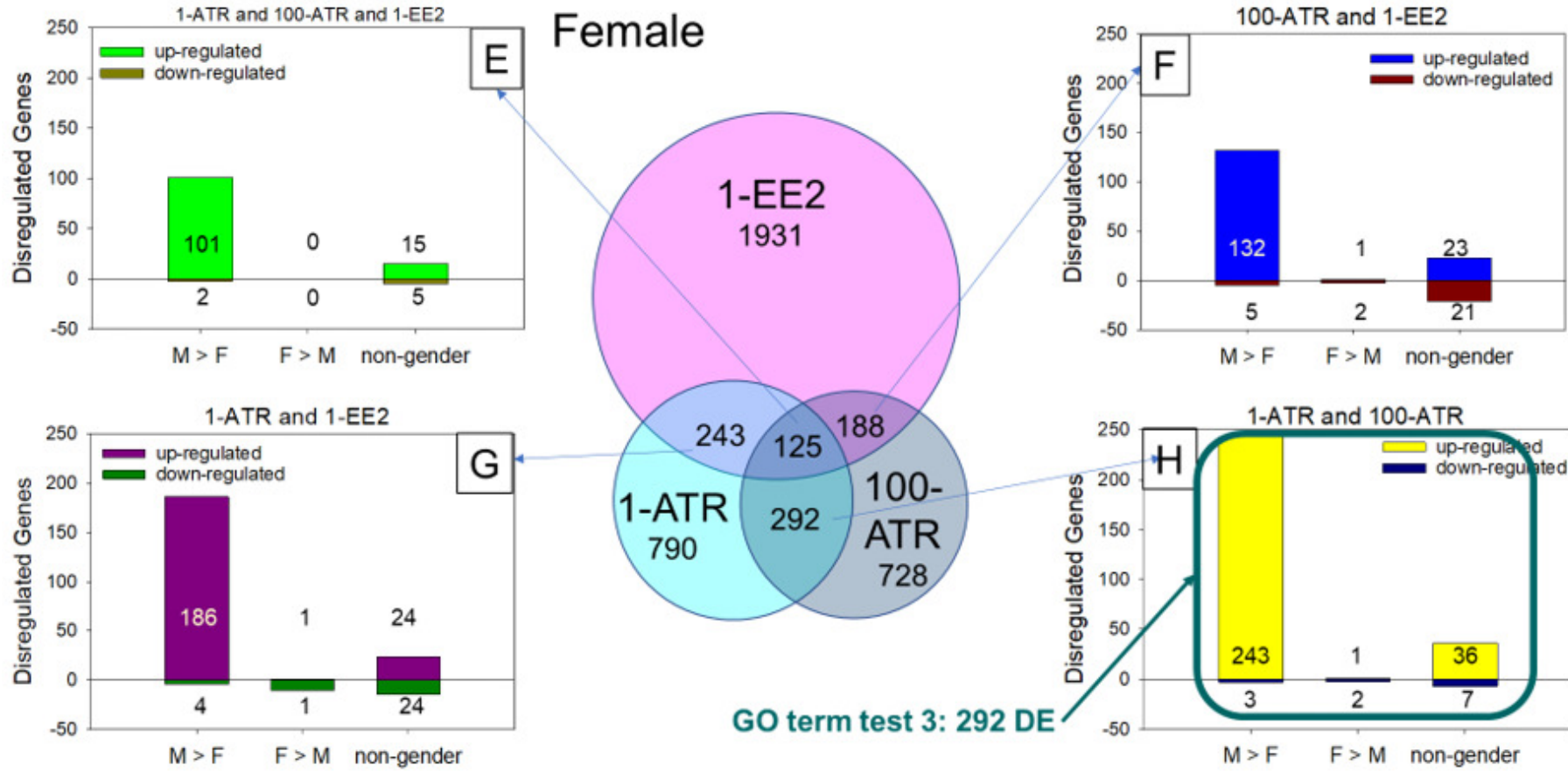

GO term test 3: $292 \mathrm{DE}$

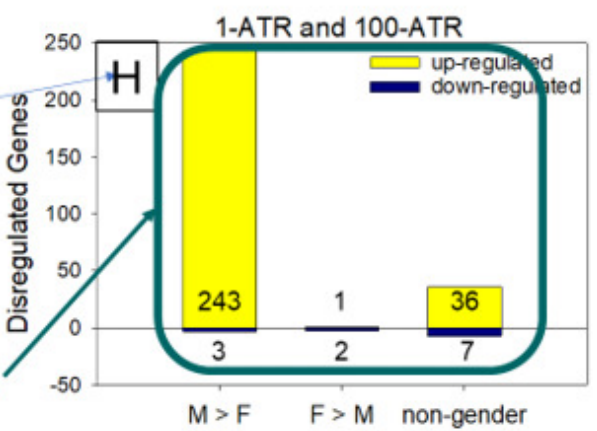




\section{Figure 5}

Differential expression data for genes of interest.

Genes of interest were based on literature search and comparative meta-analysis. Genes presented here are those that were significantly altered in one or more treatment groups. SC $=$ solvent control; 1-ATR $=1 \mu \mathrm{g} / \mathrm{L}$ Atrazine treatment; 100-ATR $=100 \mu \mathrm{g} / \mathrm{L}$ Atrazine treatment; 1-EE2 $=1 \mathrm{ng} / \mathrm{L} 17 \alpha$-ethinylestradiol treatment. Error bars are one standard deviation from the mean. The $y$-axis is in reads per million (RPM) on a log base 2 scale. Asterisk denotes significant differential expression compared to SC. Gene symbols and names: (A) cyp11a2, cytochrome P450, family 11, subfamily A, polypeptide 2; (B) star, steroidogenic acute regulatory protein; (C) cypla, cytochrome P450, family 1, subfamily A; (D) ddx4 (previously vasa), DEAD (Asp-Glu-Ala-Asp) box polypeptide 4; (E) samhd1, SAM domain and HD domain 1; (F) wnt5b, wingless-type MMTV integration site family, member $5 b$. 

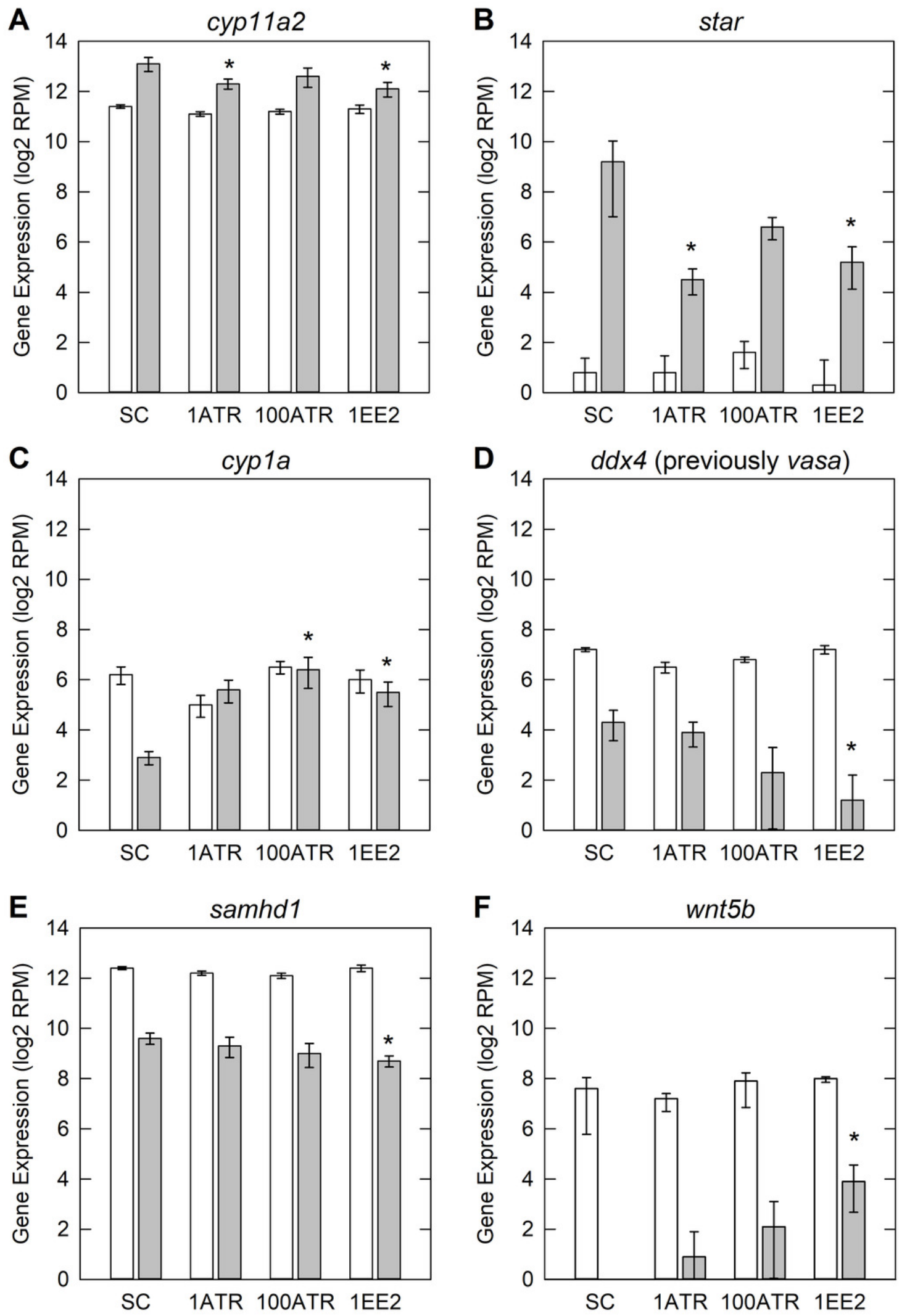


\section{Table 1 (on next page)}

Summary of growth and sex ratio data

Summary of Mean (SE) of growth and sex ratio data measured in 80 dps largemouth bass juveniles that were successfully identified as either female or male. 
1 Table 1. Summary of growth and sex ratio data. Summary of Mean (SE) of growth and sex ratio data 2 measured in 80 dps largemouth bass juveniles that were successfully identified as either female or male.

3

\begin{tabular}{|c|c|c|c|c|c|c|c|c|}
\hline \multirow[b]{2}{*}{ Treatment } & \multirow[b]{2}{*}{ Survival (\%) } & \multicolumn{2}{|l|}{$\underline{\mathbf{n}}$} & \multicolumn{2}{|c|}{ Length (mm) } & \multicolumn{2}{|l|}{ Weight (g) } & \multirow{2}{*}{$\frac{\text { Sex Ratio }}{\% \text { Female }}$} \\
\hline & & Female & Male & Female & Male & Female & Male & \\
\hline Control & $58.4(2.6)$ & 57 & 52 & $54.2(1.0)$ & $54.1(1.4)$ & $1.70(0.16)$ & $1.62(0.15)$ & $52.5(5.3)$ \\
\hline 1 ng/L EE2 & $55.6(2.2)$ & 42 & 61 & $60.3(0.4)^{*}$ & $58.3(1.4)$ & $2.37(0.15)^{*}$ & $1.95(0.11)$ & $40.3(6.4)$ \\
\hline 10 ng/L EE2 & $52.9(1.4)$ & 94 & 1 & $59.5(2.3)^{*}$ & 64.0 & $1.98(0.22)$ & 1.93 & $99.0(1.0)^{* * \dagger \dagger}$ \\
\hline $1 \mu \mathrm{g} / \mathrm{L}$ ATR & $54.0(2.9)$ & 44 & 59 & $55.8(0.6)$ & $57.1(1.5)$ & $1.68(0.09)$ & $1.48(0.13)$ & $42.7(3.5)$ \\
\hline $10 \mu \mathrm{g} / \mathrm{L}$ ATR & $58.2(2.3)$ & 38 & 56 & $58.8(1.3)$ & $56.8(2.3)$ & $2.15(0.18)$ & $1.80(0.23)$ & 39.7 (5.4) \\
\hline $100 \mu \mathrm{g} / \mathrm{L}$ ATR & $54.1(2.3)$ & 55 & 58 & 58.7 (1.1) & $60.1(1.2)$ & $2.08(0.17)$ & $2.23(0.16)$ & 48.4 (4.6) \\
\hline
\end{tabular}

$4 *=\mathrm{p}<0.05, * *=\mathrm{p}<0.01$ for treatment means significantly different from control tested by Dunnett's

5 post hoc

$6 \dagger=\mathrm{p}<0.05, \dagger=\mathrm{p}<0.01$ for sex ratios significantly different than expected 1:1 female:male tested by

7 chi-square analysis

8

9 


\section{Table 2 (on next page)}

Overrepresented GO terms for gene sets of interest

Gene ontology analysis of differentially expressed (DE) annotated transcripts identified by gene set 1,2 , or 3 . Only GO terms that were significantly overrepresented ( $p$-value $<0.05$ ) are presented. Corresponding letters identify common $\mathrm{GO}$ terms between gene sets. 


\begin{tabular}{|c|c|c|c|c|c|c|c|}
\hline Gene sets & Category & p-value & $\begin{array}{c}\text { \# DE } \\
\text { genes }\end{array}$ & $\begin{array}{r}\text { \# genes in } \\
\text { category }\end{array}$ & GO term & $\begin{array}{l}\text { \# genes } \\
\text { down- } \\
\text { regulated }\end{array}$ & $\begin{array}{l}\text { \# genes up- } \\
\text { regulated }\end{array}$ \\
\hline \multirow{6}{*}{$\begin{array}{l}\text { 1: Female specific } \\
\text { transcripts altered in } \\
\text { both the } 1 \mathrm{ng} / \mathrm{L} \mathrm{EE} 2 \\
\text { and } 100 \mu \mathrm{g} / \mathrm{L} \\
\text { Atrazine treatments }\end{array}$} & GO:0006605 & 0.0033 & 6 & 96 & protein targeting & 6 & \\
\hline & GO:0042254 & 0.00757 & 6 & 127 & ribosome biogenesis a & 6 & \\
\hline & GO:0007005 & 0.00975 & 5 & 89 & mitochondrion organization & 5 & \\
\hline & GO:0006913 & 0.0149 & 4 & 63 & nucleocytoplasmic transport & 4 & \\
\hline & GO:0006810 & 0.038 & 29 & 1352 & transport ${ }^{b}$ & 16 & 13 \\
\hline & GO:0044281 & 0.0473 & 14 & 564 & small molecule metabolic process ${ }^{c}$ & 12 & 2 \\
\hline \multirow{7}{*}{$\begin{array}{l}\text { 2: Transcripts altered } \\
\text { in males in both the } 1 \\
\text { and } 100 \mu \mathrm{g} / \mathrm{L} \\
\text { Atrazine treatments }\end{array}$} & GO:0006412 & 0.00131 & 14 & 282 & translation & 14 & \\
\hline & GO:0044281 & 0.00329 & 23 & 564 & small molecule metabolic process ${ }^{c}$ & 21 & 2 \\
\hline & GO:0006520 & 0.00336 & 9 & 133 & cellular amino acid metabolic process & 8 & 1 \\
\hline & GO:0055085 & 0.00382 & 22 & 495 & transmembrane transport ${ }^{\mathrm{d}}$ & 15 & 7 \\
\hline & GO:0009058 & 0.0262 & 54 & 1916 & biosynthetic process & & \\
\hline & GO:0042254 & 0.0396 & 6 & 127 & ribosome biogenesis ${ }^{\text {a }}$ & 6 & \\
\hline & GO:0008150 & 0.0464 & 203 & 8605 & Biological process & & \\
\hline \multirow{7}{*}{$\begin{array}{l}\text { 3: Transcripts altered } \\
\text { in females in both the } \\
1 \text { and } 100 \mu \mathrm{g} / \mathrm{L} \\
\text { Atrazine treatments }\end{array}$} & GO:0006810 & 0.00196 & 18 & 1352 & transport $^{\mathrm{b}}$ & 1 & 17 \\
\hline & GO:0007267 & 0.00211 & 6 & 249 & cell-cell signaling & & 6 \\
\hline & GO:0055085 & 0.00708 & 9 & 495 & transmembrane transport $^{\mathrm{d}}$ & & 9 \\
\hline & GO:0007010 & 0.0189 & 7 & 370 & cytoskeleton organization & & 7 \\
\hline & GO:0007165 & 0.026 & 19 & 1709 & signal transduction & 1 & 18 \\
\hline & GO:0002376 & 0.0271 & 7 & 428 & immune system process & & 7 \\
\hline & GO:0051604 & 0.0345 & 2 & 42 & protein maturation & & 2 \\
\hline
\end{tabular}

Table 2. Overrepresented GO terms for gene sets of interest. Gene ontology analysis of differentially expressed (DE) annotated transcripts identified by gene set 1,2 , or 3 . Only GO terms that were significantly overrepresented ( $p$-value $<0.05$ ) are presented. Corresponding letters identify common GO terms between gene sets.

6 